\title{
CHOQUES FISCAIS E SALÁRIOS REAIS: UMA ANÁLISE PARA OS ESTADOS BRASILEIROS
}

\author{
Elano Ferreira Arruda * \\ Felipe de Sousa Bastos ${ }^{\dagger}$ \\ Jỗo Paulo Rios e Silva $\ddagger$
}

\begin{abstract}
Resumo
Os efeitos da política fiscal sobre os salários reais, tanto em sua abordagem teórica quanto na empírica, não são consensuais. Este trabalho procura contribuir com a análise dos efeitos de choques fiscais sobre os salários reais para os estados brasileiros considerando as despesas orçamentárias, correntes e de investimento. Os resultados são extraídos das funções de impulso resposta, obtidas de modelos VAR em painel. As evidências apontam para o impacto positivo das despesas sobre PIB e salários reais. Esses resultados indicam que a síntese Novo Keynesiana parece explicar melhor a resposta do mercado de trabalho dos estados brasileiros a choques fiscais.
\end{abstract}

Palavras-chave: política fiscal; mercado de trabalho; VAR em painel

\begin{abstract}
The effects of fiscal policy on the real wages are not consensus, both in its theoretical and empirical approach. This paper seeks to contribute by analyzing the effects of fiscal shocks on real wage mass for the Brazilian states, considering budgetary, current and investment expenditure. The results were extracted from impulse response functions, obtained from the panel VAR models. The evidence points to the positive impact of expenditures on GDP and real wages. These results indicate that the New Keynesian synthesis seems to better explain the Brazilian labor market response to fiscal shocks.
\end{abstract}

Keywords: fiscal policy; labor market; panel VAR

JEL classification: E62, C33

DOI: http://dx.doi .org/10.11606/1980-5330/ea133068

\footnotetext{
* Professor no CAEN/MAER/UFC. E-mail: elano@ufc.br

† Doutor em Economia - CAEN/UFC. E-mail: flpsbastos@gmail.com

$\ddagger$ Doutorando em Economia - CAEN/UFC. E-mail: joaopaulorios92@gmail.com
} 


\section{Introdução}

As recentes crises financeiras têm acentuado o debate sobre o papel das políticas macroeconômicas no processo de estabilização da economia e no nível de atividade econômica, especialmente no mercado de trabalho. Nesse contexto, se discute o impacto dos choques fiscais sobre os salários reais. Todavia, tratando-se de política fiscal, tanto os modelos teóricos, quanto a evidência empírica estão longe de um consenso.

Na perspectiva teórica, as visões sobre os efeitos supracitados se mostram antagônicas tendo em vista os modelos dos Ciclos Reais de Negócios (RBC) e os modelos de tradição Novo Keynesiana (NK). Os primeiros advogam que os agentes econômicos entendem aumentos não previstos nos gastos públicos no tempo corrente como incrementos de impostos no futuro e, portanto, ofertariam mais trabalho no presente. O excesso de oferta de trabalho, em um ambiente de preços flexíveis, reduziria o nível dos salários; ou seja, os choques fiscais impactariam negativamente os salários. Para a perspectiva NK, os aumentos de gastos públicos apresentariam resultados semelhantes aos anteriores, todavia a demanda por trabalho também aumentaria e em uma magnitude maior do que a oferta de trabalho, o que, em um ambiente de rigidez de preços, produziria aumento no salário real dos agentes econômicos.

A literatura empírica também está longe de obter uma evidência unânime no que tange aos efeitos de choques fiscais sobre o mercado de trabalho. Por exemplo, Ramey \& Shapiro (1998), Burnside et al. (2004) observam efeitos negativos dos gastos militares sobre os salários reais e consumo das famílias. Utilizando medidas mais gerais de gastos públicos, Aiyagari et al. (1992), e Baxter \& King (1993) encontram evidências de reduções salariais frente a incrementos nos gastos públicos, resultados sustentados pelos modelos RBC. Já autores como Rotemberg \& Woodford (1992), Galí et al. (2007) obtiveram resultados que sustentam a tradição NK. Vale destacar que, em estudo recente para o Brasil, Carvalho et al. (2013) também observam resultados empíricos na direção da visão NK.

Apesar de a maioria dos estudos focar em análises para dados em painel de países, Pappa (2009) adverte que esse tipo de investigação pode se mostrar mais precisa considerando dados intranacionais, ou de unidades federativas, uma vez que, nesse contexto, a política monetária e o regime cambial podem ser tomados como dados e, ainda, existem muitas dificuldades na construção de painéis para países com dados sobre choques fiscais que sejam comparáveis, em virtude da diversificação do padrão de coleta dos dados. Ainda nessa linha, Partridge \& Rickman (2010) argumentam que os modelos econômicos regionais são construídos a partir de seus congêneres nacionais e que técnicas macroeconométricas como Vetores Autorregressivos (VAR), VAR restrito, VAR em painéis de dados, VAR estrutural (SVAR) e os modelos de Equilíbrio Geral Dinâmico Estocásticos (DSGE) têm sido subutilizadas em economia regional. Para o autor, esses arcabouços podem produzir importantes evidências empíricas para o entendimento de relações macroeconômicas em um contexto regional.

Portanto, o presente estudo tem por objetivo analisar os efeitos dos choques fiscais sobre os salários reais para os estados brasileiros utilizando as funções impulso resposta acumuladas (AIRF) extraídas de um VAR em painel (PVAR). Para tal, utilizar-se-á um painel de dados anuais que cobre o período de 1995 a 2010, para 26 unidades da federação e o Distrito Federal. 
O presente trabalho inova ao aplicar um modelo PVAR para os estados brasileiros de modo a examinar, em um contexto regional (Partridge \& Rickman 2010), os efeitos das despesas públicas orçamentárias, correntes e de investimento sobre os salários reais. Adicionalmente, serão considerados exercícios de robustez para vários subperíodos distintos e para painéis que consideram diferentes regiões do país de modo a identificar possíveis assimetrias nessas respostas.

A partir desse exercício, será possível inferir sobre o comportamento do mercado de trabalho nos estados brasileiros: se ele se comporta como a tradição RBC, com resposta negativa, ou se choques fiscais aumentam salários reais, como nos modelos NK. Vale destacar que, por se tratarem de dados intranacionais, as assimetrias de política monetária podem ser tomadas como dadas para todos os estados e, ainda, Bénétrix (2012) defende que esse tipo de estudo se paute em dados anuais, pois, uma vez que a política fiscal normalmente tem caráter anual, esses dados são menos afetados por alterações sazonais e minimizam os chamados efeitos de antecipação dos choques fiscais.

Além desta introdução, este trabalho possui mais quatro seções. A próxima consiste em destacar os aspectos teóricos e empíricos que versam os impactos dos choques fiscais sobre o mercado de trabalho, especialmente sobre os salários reais. A Seção 3 se reserva à apresentação do banco de dados e da estratégia econométrica empregada. Os resultados dos modelos são apresentados e discutidos na 4 Seção. Por fim, são tecidas as considerações finais do estudo.

\section{Revisão de Literatura}

A literatura que investiga os efeitos dos gastos públicos sobre o mercado de trabalho, especialmente sobre os salários, é ampla. De forma geral, os resultados concentram-se em duas vertentes: modelos Novos Keynesianos (NK), que advogam que os gastos públicos impactam positivamente os salários reais e aqueles que argumentam que o impacto do consumo do governo gera um excesso de oferta de trabalho e, portanto, afeta negativamente os salários reais, os modelos dos Ciclos Reais de Negócios (RBC).

Entre os autores que observaram evidências em favor da tradição RBC, destacam-se Aiyagari et al. (1992), Baxter \& King (1993), Ramey \& Shapiro (1998) e Burnside et al. (2004). Os primeiros mostram, em um modelo de crescimento estocástico Neoclássico e utilizando dados trimestrais de 1955 a 1983 nos Estados Unidos, sob a suposição de que os gastos governamentais são financiados via impostos do tipo lump-sum, que o impacto de uma mudança persistente no consumo do governo sobre o produto agregado e o emprego sempre excede em magnitude o efeito de uma mudança temporária - do ponto de vista teórico e empírico. Adicionalmente, observam efeitos negativos dos gastos públicos sobre os salários.

Baxter \& King (1993) estudam 4 experimentos clássicos de política fiscal dentro de um modelo neoclássico restrito quantitativamente e apontam os seguintes achados: variações permanentes no consumo do governo tem implicações importantes na atividade macroeconômica quando são financiadas via impostos do tipo lump sum, podendo levar a multiplicadores do produto de curto prazo - se a oferta de trabalho reportar alta elasticidade - e longo prazo maiores que 1. Portanto, por apresentar uma oferta de trabalho mais elástica, 
os salários reais tendem a responder negativamente a aumentos nos gastos públicos.

Examinando possíveis assimetrias nas respostas da demanda agregada aos gastos públicos por setores, Ramey \& Shapiro (1998) utilizam um modelo dinâmico de equilíbrio geral computável e observam que aumentos nos gastos militares impactam negativamente os salários reais.

Burnside et al. (2004) investigam a resposta das horas trabalhadas e do salário real a choques fiscais nos Estados Unidos no período pós-Segunda Guerra Mundial, identificando choques fiscais que são seguidos por declínio persistente no salário real, aumento das horas trabalhadas e movimentos no consumo. Adicionalmente, verificam se duas versões do modelo neoclássico suportam estas descobertas: (i) a versão benchmark ${ }^{1}$ reporta algumas falhas, sobretudo quando impostos distorcivos são levados em conta; (ii) já a versão com fricções - formação de hábitos no consumo e custo de ajustes no investimento - apresenta melhora na performance qualitativa, apesar de superestimar o declínio do consumo após o choque.

Visando elucidar a condução ótima da política fiscal e monetária para o Brasil no período pós-Plano Real, Lobato (2011) utiliza um modelo DSGE de médio porte, comportando 4 fontes de rigidez nominal: rigidez de preços e salários, demanda por moeda e uma restrição cash-in-advance para a massa salarial das firmas, buscando explicar os movimentos cíclicos de diversas variáveis. Os autores estimam um efeito negativo da taxa de salários a um choque nos gastos do governo.

Por outro lado, alguns autores encontram efeitos positivos nos salários reais frente a choques nos gastos do governo, corroborando com a vertente Novo Keynesiana. Modelando as consequências da existência de competição imperfeita para as flutuações da demanda agregada, Rotemberg \& Woodford (1992) argumentam que os choques de demanda agregada - mudança no consumo do governo - sobre a atividade econômica são consequência de competição imperfeita. Comparando resultados entre os modelos de competição perfeita e o modelo de competição oligopolista, os autores constatam que a principal diferença entre os dois é a resposta dos salários reais a um choque nas despesas militares, com o segundo modelo apresentando resposta positiva.

Galí et al. (2007), por meio de dados trimestrais da economia norte-americana, estimam as reações de uma série de variáveis macroeconômicas a um choque no gasto do governo por meio de um modelo VAR, assumindo que os choques não são afetados contemporaneamente (durante o trimestre) pelas outras variáveis contidas no modelo. Os resultados expressam uma reação positiva aos choques tanto para horas trabalhadas como para os salários reais, embora se observe certa defasagem da reação ao choque nessas duas variáveis.

Para explorar o papel adicional do efeito riqueza na transmissão de choques de gastos governamentais, Monacelli \& Perotti (2008) constroem um modelo RBC com rigidez de preço, em que as preferências podem ser consistentes com efeito riqueza arbitrariamente pequenos sobre a oferta de trabalho. Feito isso, os autores mostram que esse modelo é compatível com as evidências empíricas sobre os choques de gastos do governo - aumento do consumo privado, salário real e queda do mark-up.

Ramey (2011) observa que os modelos que internalizam choques fiscais no trimestre tendem a estimar efeitos positivos destes sobre salários reais e con-

\footnotetext{
${ }^{1} \mathrm{O}$ modelo de Ciclos Reais dos Negócios (RBC) tradicional, isto é, sem fricções.
} 
sumo. Além disso, os modelos Novo Keynesianos tendem a conter uma série de pressuposições a respeito do comportamento do consumo, preços e oferta de trabalho. Comparando o modelo neoclássico descrito em Ramey \& Shapiro (1998) com os modelos VAR Novo Keynesianos, a autora demonstra que choques nas despesas militares nos Estados Unidos são antecipados trimestres antes de ocorrerem, atribuindo a diferença de resultados sobre salários reais e consumo ao efeito antecipação.

Forni et al. (2009) estimam um modelo DSGE com agentes que seguem comportamento não Ricardiano para estimar os efeitos das políticas fiscais na Zona do Euro. O modelo leva em consideração os impostos sobre capital e trabalho, enquanto avalia separadamente os impactos do consumo do governo, rendimentos do setor público e transferências para as famílias. Os resultados das estimações do modelo, utilizando dados trimestrais, corroboram para a abordagem Novo Keynesiana sobre o impacto dos choques fiscais nas variáveis econômicas, com choques nas transferências para as famílias exercendo efeitos mais duradouros do que os choques no consumo do governo e nos rendimentos do setor público. Entretanto, levando-se em consideração apenas o efeito sobre os salários reais, choques sobre consumo do governo e rendimentos do setor público parecem exercer maior impacto.

Mountford \& Uhlig (2009) buscam responder quais os efeitos de cortes de impostos na economia e quais implicações desse corte ser financiado via cortes de gastos ou aumento da dívida pública. Sem impor qualquer restrição de sinal sobre a resposta de variáveis-chave - PIB, consumo privado, investimento privado não residencial e salário real - ao choque de política fiscal e impondo restrições de ortogonalidade para choques de ciclos de negócios e de política monetária, os autores analisam 3 cenários: gastos deficitários, redução de impostos financiada com déficit e uma expansão de gastos com orçamento equilibrado. Ao comparar esses cenários, encontram que um corte de impostos surpresa financiado com déficit é a melhor política fiscal para estimular a economia.

Pappa (2009) se concentra na reação do mercado de trabalho a choques de despesa do governo. Utilizando um VAR estrutural e identificando os choques via restrição de sinal. Sua estratégia de identificação é baseada na ideia de que o choque fiscal aumenta o produto e o déficit - resultado obtido a partir dos modelos RBC e Novo Keynesiano. A autora encontra que aumentos no consumo ou investimento do governo expandem o salário real e o emprego no período corrente nos Estados Unidos, com resultado semelhante para dados dos estados norte-americanos.

Fisher \& Peters (2010) exploram uma nova abordagem a respeito do impacto dos choques fiscais em diversas variáveis macroeconômicas, evitando as fragilidades encontradas tanto nos modelos Novo Keynesianos como nos modelos neoclássicos. Os autores consideram choques nas despesas militares do governo americano como exógenos, entretanto, admitem que os agentes formam expectativas definidas a partir do retorno das ações de empresas da indústria armamentista americana, antecipando com isso o efeito dos choques. O modelo retorna um efeito inicialmente negativo de um choque nas despesas militares dos Estados Unidos sobre os salários reais, mas que logo se reverte em positivo, mostrando que o efeito negativo dessas despesas sobre os salários reais possui curta duração.

Buscando contornar o efeito da antecipação dos agentes a choques fiscais, particularmente em seus efeitos sobre salários reais e consumo, Mertens \& 
Ravn (2010) desenvolveram um estimador fiscal para o modelo SVAR aplicável quando os choques são antecipados, realizando um exercício empírico por meio de dados macroeconômicos trimestrais dos Estados Unidos, particularmente, consumo, produto e gastos do governo. Embora não tenham encontrado evidências de que as antecipações à política fiscal revertam os resultados já corroborados pelos modelos SVAR tradicionais, os autores encontram respostas positivas do consumo e do produto a um choque fiscal.

Em um painel com 11 países-membros da Zona do Euro, Bénétrix (2012) encontra que um aumento dos gastos governamentais eleva o salário real, destacando que a magnitude do impacto está relacionada ao tipo de gasto. $\mathrm{O}$ autor aponta que o investimento governamental possui o maior impacto positivo dentre as componentes de gasto analisadas, enquanto o número de funcionários públicos não exerce qualquer impacto.

Em um exame para a economia brasileira, Carvalho et al. (2013) utilizam um modelo de Equilíbrio Geral Dinâmico e Estocástico (DSGE), que segue a Nova Síntese Neoclássica, para identificar o sinal das variáveis como estratégia para identificação do choque fiscal em um SVAR. Os resultados mostram que choques fiscais aumentam o salário real e o emprego, o que sugere que os choques deslocam a demanda por trabalho.

Diante do exposto, o presente artigo pretende contribuir para essa literatura com uma análise dos efeitos dos choques fiscais sobre os salários reais, considerando modelos regionais para os estados brasileiros, nos moldes sugeridos por Partridge \& Rickman (2010).

\section{Aspectos Metodológicos}

\subsection{Descrição dos Dados}

Para avaliar os efeitos de choques fiscais sobre os salários reais - extraídos do banco da Relação Anual de Informações Sociais (RAIS) -, foram obtidas informações das seguintes despesas junto ao banco de dados do Instituto de Pesquisa Econômica Aplicada (IPEADATA): despesa orçamentária, corrente e de investimento. Os dados de Produto Interno Bruto (PIB) foram obtidos no Instituto Brasileiro de Geografia e Estatística (IBGE). O painel de dados cobre o período de 1995 a 2010 para 26 unidades da federação e o Distrito Federal. O quadro abaixo sintetiza as variáveis utilizadas.

Existem algumas vantagens no uso de dados anuais, dentre elas: (i) choques fiscais podem ser melhor interpretados, pois a política fiscal não é substancialmente revista dentro de um ano; (ii) a probabilidade de efeitos antecipação, isto é, a chance dos agentes anteciparem um choque fiscal, é menor; e (iii) dados anuais são menos afetados por mudanças sazonais (Bénétrix 2012).

É possível elencar também benefícios decorrentes do uso de dados para Unidades da Federação (UFs) dentro de um mesmo país. Com dados dessa natureza, a política monetária pode ser tomada como dada na análise e, uma vez que dados comparáveis internacionais sobre variáveis fiscais são difíceis de encontrar, esse tipo de análise pode caracterizar de forma transversal a dinâmica de transição do choque fiscal e dar algumas indicações do que se deveria esperar encontrar em grandes regiões econômicas de mesma moeda (Pappa 2009).

Na Figura 1, observa-se a evolução da média das despesas correntes, de investimento e orçamentária, e do salário real médio por trabalhador das UFs 
Tabela 1: Descrição das variáveis

\begin{tabular}{|c|c|c|c|}
\hline Variável & Definição & Período & Fonte \\
\hline $\begin{array}{l}\text { Despesa } \\
\text { Orçamen- } \\
\text { tária }\end{array}$ & $\begin{array}{l}\text { Despesa Orçamentária: depende de auto- } \\
\text { rização legislativa para ser realizada. É, } \\
\text { grosso modo, dividida em despesas corren- } \\
\text { tes e de capital. }\end{array}$ & $1995-2010$ & IPEADATA \\
\hline $\begin{array}{l}\text { Despesa } \\
\text { Corrente }\end{array}$ & $\begin{array}{l}\text { Despesa Corrente: componente da despesa } \\
\text { orçamentária, corresponde as despesas que } \\
\text { não contribuem diretamente para a aquisi- } \\
\text { ção (ou formação) de um bem de capital. } \\
\text { Diz respeito a despesas necessárias a manu- } \\
\text { tenção de serviços criados anteriormente, } \\
\text { dentre outros. }\end{array}$ & $1995-2010$ & IPEADATA \\
\hline $\begin{array}{l}\text { Despesa } \\
\text { de Investi- } \\
\text { mento }\end{array}$ & $\begin{array}{l}\text { Despesa de Investimento: são despesas que } \\
\text { englobam as dotações para o planejamento } \\
\text { e a execução de obras, aquisição de instala- } \\
\text { ções, equipamentos e material permanente, } \\
\text { e constituição ou aumento do capital de em- } \\
\text { presas que não sejam de caráter comercial } \\
\text { ou financeiro. }\end{array}$ & $1995-2010$ & IPEADATA \\
\hline $\begin{array}{l}\text { Salário } \\
\text { Real } \\
\text { Médio }\end{array}$ & $\begin{array}{l}\text { Salário Real Médio por Trabalhador: repre- } \\
\text { senta a média de rendimentos mensais re- } \\
\text { cebidos por trabalhador em cada ano. }\end{array}$ & $1995-2010$ & RAIS \\
\hline PIB & $\begin{array}{l}\text { Produto Interno Bruto: soma de todos os } \\
\text { bens e serviços finais produzidos pelo Es- } \\
\text { tado dentro de um determinado período. }\end{array}$ & $1995-2010$ & IBGE \\
\hline
\end{tabular}

Fonte: Elaborado pelos autores. Nota: 1. As variáveis de PIB e gastos públicos foram deflacionadas pelo deflator implícito do PIB e pelo Índice Geral de Preço - disponibilidade interna (IGP-DI), ambos com base $2012=100$. 2. O salário real médio foi deflacionado pelo deflator de rendimentos da PNAD, também com base $2012=100$.

e Distrito Federal. Como é de se esperar, visto que as despesas correntes e de investimento são componentes do orçamento, as despesas orçamentárias representam um montante superior ao das demais despesas e apresenta, juntamente com as despesas correntes, tendência crescente ao longo do tempo. Já as despesas de investimento permanecem relativamente constantes, com picos nos anos de 1997 e 1998. O indicador de salário real médio por trabalhador, alinhado ao eixo vertical à direita, apresentou leve crescimento nos intervalos de 1995-2000 e de 2003-2010, mas permanecendo relativamente estável, em torno de $1.370,00$ reais.

As estatísticas descritivas das variáveis utilizadas encontram-se expostas na Tabela 2. O indicador salário real por trabalhador reportou média mensal em torno de 1.374,35 reais, oscilando entre 1.237,08 e 1.531,18 reais, sendo esta a variável que apresentou menor grau de dispersão. Dentre as despesas, a despesa orçamentária apresentou maior montante médio, com 16.320,06 milhões de reais e dispersão de 2.675,08 milhões de reais. É importante considerar a amplitude das despesas correntes, de cerca de 7.987,43 milhões de reais, indicando grau considerável de disparidade entre as despesas não relacionadas à formação de capital. Já o PIB médio do período, de 123.079,10 milhões de reais, oscilou dentro do intervalo de $107.265,77$ e $160.590,88$ milhões de reais. 
Figura 1: Evolução da média dos indicadores de despesa de investimento, corrente e orçamentária, deflacionadas pelo IGP-DI, e do salário real médio por trabalhador

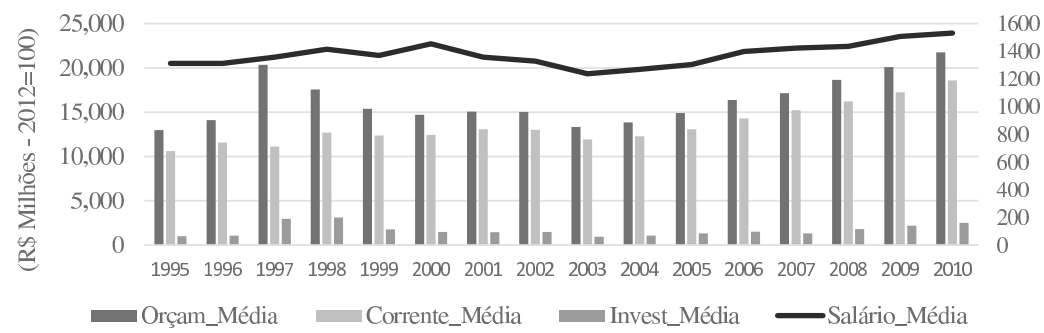

Fonte: Elaborado pelos autores.

Tabela 2: Análise descritiva

\begin{tabular}{lrrrr}
\hline \multirow{2}{*}{ Variáveis } & Média & Desvio-padrão & \multicolumn{2}{c}{ Amplitude } \\
\cline { 4 - 5 } & & & \multicolumn{1}{c}{ Mínimo } & \multicolumn{1}{c}{ Máximo } \\
\hline Orçamentária Média & $16.320,06$ & $2.675,08$ & $12.971,00$ & $21.753,42$ \\
Corrente Média & $13.478,60$ & $2.254,84$ & $10.606,69$ & $18.594,12$ \\
Investimento Média & $1.685,52$ & 673,00 & 937,32 & $3.105,40$ \\
PIB Média & $123.079,10$ & $14.799,77$ & $107.265,77$ & $160.590,88$ \\
Salário Média & $1.375,35$ & 82,55 & $1.237,08$ & $1.531,18$ \\
\hline
\end{tabular}

Fonte: Elaborado pelos autores a partir de dados do IPEA/IBGE/RAIS. Nota: Com exceção do salário real médio por trabalhador, as demais variáveis estão na escala de milhões de reais e foram deflacionadas pelo IGP-DI.

\subsection{Estratégia Econométrica}

Para examinar os efeitos dos choques fiscais sobre os salários reais nos estados brasileiros, considerando as despesas orçamentárias, correntes e de investimentos, utilizar-se-á uma adaptação do modelo empírico PVAR nos moldes de Bénétrix (2012) para cada tipo de gasto.

$$
Z_{i, t}=B(L) Z_{i, t-1}+D X_{i, t}+u_{i, t}
$$

A forma estrutural desse modelo é dada por $A_{0} Z_{i, t}=A(L) Z_{i, t-1}+C X_{i, t}+\epsilon_{i, t}$ em que $A(L)=A_{0} B(L), C=A_{0} D, \epsilon_{i, t}=A_{0} u_{i, t}$ e, ainda,

$$
Z_{i, t}=\left(\begin{array}{c}
G_{i, t} \\
Y_{i, t} \\
W_{i, t}
\end{array}\right) ; A_{0}=\left(\begin{array}{ccc}
1 & -a_{y g} & a_{w g} \\
-a_{g y} & 1 & a_{w y} \\
-a_{g w} & a_{y w} & 1
\end{array}\right) ; X_{i, t}=\left(\begin{array}{c}
c_{i} \\
t_{t} \\
d_{t}
\end{array}\right) ; \epsilon_{i, t}=\left(\begin{array}{c}
\epsilon_{i, t}^{g} \\
\epsilon_{i, t}^{y} \\
\epsilon_{i, t}^{w}
\end{array}\right)
$$

em que $i$ e $t$ denotam o estado e o ano, respectivamente. $Z_{i, t}$ é o vetor de variáveis endógenas, quais sejam, os gastos públicos, $G_{i, t}$, o PIB estadual, $Y_{i, t}$ e o salário real, $W_{i, t}$. A matriz $A_{0}$ captura as relações contemporâneas entre os regressores. A matriz $A(L)$ é a matriz que incorpora os efeitos das variáveis endógenas e suas defasagens. Todas as variáveis estão expressas em logaritmo.

Como se utiliza um modelo com dados em painel, é importante levar em consideração a heterogeneidade não observada dos estados. Por isso, utilizarse-á o estimador de efeitos fixos, por mínimos quadrados com variáveis dummies (LSDV) para dados em painel, em que $c_{i}$, no vetor $X_{i, t}$, incorpora o efeito 
específico de cada unidade cross-section. Vale destacar que Nikell (1981) e Hahn \& Kuersteiner (2002) mostram que o estimador LSDV se mostra consistente para painéis com dimensão temporal razoavelmente grande. Adicionalmente, no vetor $X_{i, t}$, foram incorporadas tendências temporais, $t_{t}$, e uma dummy indicativa para a lei de responsabilidade fiscal, $d_{2000}$. Por fim, $\epsilon_{i, t}$ contém os choques estruturais ortogonais.

A estratégia de identificação adotada no processo de estimação foi o ordenamento recursivo, como em Blanchard \& Perotti (2002), Perotti et al. (2005), Monacelli \& Perotti (2010) e Bénétrix (2012). Assume-se que os gastos públicos não são afetados pelas demais variáveis dentro do mesmo ano, que o PIB é explicado pelos gastos públicos e que os salários reais são influenciados por ambos os indicadores; noutros termos, admite-se que $a_{y} g=a_{w} g=a_{w} y=0$. Beetsma et al. (2009) também advogam em favor desse ordenamento, dada a previsão dos modelos keynesianos tradicionais, que tratam os gastos públicos como exógenos em relação ao PIB, e, ainda, encontram evidências de nenhum efeito contemporâneo do PIB sobre os gastos do governo. Outro aspecto relevante a considerar é que, ao colocar o PIB antes dos gastos públicos no ordenamento, impõe-se que o primeiro não é afetado pelo segundo, o que é uma incoerência, uma vez que os gastos públicos contribuem na composição do PIB.

Após a estimação, as evidências das respostas dos salários reais aos choques fiscais serão extraídas a partir das funções de impulso resposta acumuladas (AIRF's). Os intervalos de confiança para as AIRF's serão obtidos por meio do procedimento de bootstrap proposto por Hall (1992).

Em suma, a estratégia econométrica pode ser assim resumida: inicialmente analisar-se-á a ordem de integração das séries e, aquelas que se mostrarem I(1), isto é, estacionárias em primeira diferença, serão incorporadas ao modelo em termos de suas taxas de crescimento; em seguida, proceder-se-á a estimação de três modelos PVAR, um para cada tipo de despesa pública utilizada, dos quais serão extraídas as AIRF's e seus respectivos intervalos de confiança obtidos por meio do procedimento de bootstrap proposto por Hall (1992). Cada modelo será estimado com as variáveis deflacionadas pelo IGP-DI. De modo a analisar a robustez dos resultados, os modelos são posteriormente estimados com as variáveis deflacionadas pelo deflator do PIB. Dessa forma, haverá um total de seis modelos na análise principal.

\section{Resultados}

Para analisar os efeitos dos choques fiscais sobre os salários reais, analisou-se inicialmente a ordem de integração das séries utilizadas por meio dos testes de Levin et al. (2002) - LLC, que tem como hipótese nula a presença de uma raiz unitária comum a todas as unidades no painel, e Im, Im et al. (2003) IPS, que testam a presença de raiz unitária individual nos cross-section. Os resultados estão sintetizados na Tabela 3.

Os testes de Levin et al. (2002) e Im et al. (2003) indicam que apenas a série de salários reais se mostrou estacionária em nível e que todas as demais séries se mostraram integradas de primeira ordem, I(1). Como todas as variáveis estão em logaritmo, as representações em primeira diferença expressam suas taxas de crescimento. Assim, nos modelos estimados, todas as variáveis de gastos e PIB serão incluídas em termos de suas taxas de crescimento. 
Tabela 3: Resultados dos testes de raiz unitária

\begin{tabular}{|c|c|c|c|c|}
\hline \multirow{2}{*}{\multicolumn{2}{|c|}{ Variável }} & \multicolumn{3}{|c|}{ Teste } \\
\hline & & LLC & IPS & Resultado \\
\hline \multirow{2}{*}{ Ln(Salário Real) } & Nível & $\begin{array}{l}-3,79^{*} \\
(0,00)\end{array}$ & $\begin{array}{l}-1,55^{*} \\
(0,05)\end{array}$ & \multirow[b]{2}{*}{$\mathrm{I}(0)$} \\
\hline & Primeira Diferença & $\begin{array}{r}-19,37^{*} \\
(0,00)\end{array}$ & $\begin{array}{l}-2,83^{*} \\
(0,00)\end{array}$ & \\
\hline \multirow{2}{*}{$\begin{array}{l}\text { Ln(Despesa Inves- } \\
\text { timento Deflator) }\end{array}$} & Nível & $\begin{array}{c}1,25 \\
(0,89)\end{array}$ & $\begin{array}{c}-0,63 \\
(0,26)\end{array}$ & \multirow[b]{2}{*}{$\mathrm{I}(1)$} \\
\hline & Primeira Diferença & $\begin{array}{r}-6,02^{*} \\
(0,00) \\
\end{array}$ & $\begin{array}{r}-8,82^{*} \\
(0,00) \\
\end{array}$ & \\
\hline \multirow{2}{*}{$\begin{array}{l}\text { Ln(Despesa Inves- } \\
\text { timentoo IGP-DI) }\end{array}$} & Nível & $\begin{array}{c}1,41 \\
(0,92)\end{array}$ & $\begin{array}{c}-0,78 \\
(0,21)\end{array}$ & \multirow[b]{2}{*}{$\mathrm{I}(1)$} \\
\hline & Primeira Diferença & $\begin{array}{c}-5,49^{*} \\
(0,00)\end{array}$ & $\begin{array}{r}-8,56^{*} \\
(0,00)\end{array}$ & \\
\hline \multirow{2}{*}{$\begin{array}{l}\text { Ln(Despesa Orça- } \\
\text { mento Deflator) }\end{array}$} & Nível & $\begin{array}{c}2,22 \\
(0,98)\end{array}$ & $\begin{array}{c}-4,66 \\
(1,00)\end{array}$ & \multirow[b]{2}{*}{$\mathrm{I}(1)$} \\
\hline & Primeira Diferença & $\begin{array}{r}-19,81^{*} \\
(0,00)\end{array}$ & $\begin{array}{r}-16,75^{*} \\
(0,00)\end{array}$ & \\
\hline \multirow{2}{*}{$\begin{array}{l}\text { Ln(Despesa Orça- } \\
\text { mento IGP-DI) }\end{array}$} & Nível & $\begin{array}{c}3,50 \\
(0,99)\end{array}$ & $\begin{array}{c}4,48 \\
(1,00)\end{array}$ & \multirow[b]{2}{*}{$\mathrm{I}(1)$} \\
\hline & Primeira Diferença & $\begin{array}{r}-19,93^{*} \\
(0,00)\end{array}$ & $\begin{array}{r}-15,48^{*} \\
(0,00)\end{array}$ & \\
\hline \multirow{2}{*}{$\begin{array}{l}\text { Ln(Despesa Cor- } \\
\text { rente Deflator })\end{array}$} & Nível & $\begin{array}{r}-4,95 \\
(1,00)\end{array}$ & $\begin{array}{c}8,82 \\
(0,99)\end{array}$ & \multirow[b]{2}{*}{$\mathrm{I}(1)$} \\
\hline & Primeira Diferença & $\begin{array}{r}-18,30^{*} \\
(0,00)\end{array}$ & $\begin{array}{r}-14,75^{*} \\
(0,00)\end{array}$ & \\
\hline \multirow{2}{*}{$\begin{array}{l}\text { Ln(Despesa Cor- } \\
\text { rente IGP-DI) }\end{array}$} & Nível & $\begin{array}{c}7,08 \\
(1,00)\end{array}$ & $\begin{array}{c}9,25 \\
(1,00)\end{array}$ & \multirow[b]{2}{*}{$\mathrm{I}(1)$} \\
\hline & Primeira Diferença & $\begin{array}{r}-15,62^{*} \\
(0,00)\end{array}$ & $\begin{array}{r}-12,16^{*} \\
(0,00)\end{array}$ & \\
\hline \multirow{2}{*}{ Ln(PIB Deflator $)$} & Nível & $\begin{array}{l}13,28 \\
(1,00)\end{array}$ & $\begin{array}{l}16,10 \\
(1,00)\end{array}$ & \multirow[b]{2}{*}{$\mathrm{I}(1)$} \\
\hline & Primeira Diferença & $\begin{array}{r}-12,06^{*} \\
(0,00)\end{array}$ & $\begin{array}{r}-9,71^{*} \\
(0,00)\end{array}$ & \\
\hline \multirow{2}{*}{$\operatorname{Ln}(P I B I G P-D I)$} & Nível & $\begin{array}{l}13,90 \\
(1,00)\end{array}$ & $\begin{array}{l}15,51 \\
(1,00)\end{array}$ & \multirow[b]{2}{*}{$\mathrm{I}(1)$} \\
\hline & Primeira Diferença & $\begin{array}{l}-4,16^{*} \\
(0,00)\end{array}$ & $\begin{array}{l}-3,86^{*} \\
(0,00)\end{array}$ & \\
\hline
\end{tabular}

Fonte: Elaborado pelos Autores a partir dos resultados obtidos. Nota: p-valor entre parênteses. * Significante ao nível de 5\%.

Portanto, são estimados modelos PVAR nos moldes da Seção 3 considerando as taxas de crescimento dos gastos orçamentários, dos gastos correntes e dos gastos de investimento, como variáveis fiscais. Ressalta-se que, como as séries originais são deflacionadas tanto pelo IGP-DI como pelo deflator, são estimados dois modelos para cada tipo de gasto analisado, totalizando seis modelos.

Os resultados são apresentados nas Tabelas A.1 a A.3, em apêndice. O critério de informação de Schwartz indicou 1 como o número ótimo de lags em todos os modelos analisados. Em seguida partiu-se para a análise das AIRF's, que se encontram sintetizadas na Figura 2. Vale destacar que as figuras 
das AIRF's à esquerda indicam o modelo com as variáveis deflacionadas pelo deflator do PIB, e à direita aquelas com as séries deflacionadas pelo IGP-DI. Os resultados são apresentados e discutidos nas subseções seguintes.

\subsection{Choques nas Despesas Orçamentárias}

Após a estimação dos modelos que consideram a taxa de crescimento dos gastos orçamentários como indicador fiscal, observaram-se inicialmente os coeficientes estruturais, ou de efeitos contemporâneos, no sistema. Os resultados são detalhados na Tabela A.1. As evidências indicam, no modelo que utiliza o deflator do PIB, que um aumento de 1 p.p. na taxa de crescimento das despesas orçamentárias aumentam em 0,042 p.p. o crescimento do PIB dos estados e em $0,06 \%$ os salários reais ${ }^{2}$. Já na análise com as séries deflacionadas pelo IGP-DI, esses impactos foram de 0,13 p.p. e 0,09\%, respectivamente. Se o aumento de 1 p.p. fosse na taxa de crescimento do PIB, os salários reais seriam majorados em $0,079 \%$ no modelo que usa o deflator e em $0,26 \%$ na análise com o IGP-DI. Em seguida, analisaram-se as AIRF's.

Observa-se na Figura 2 que o PIB dos estados brasileiros apresenta uma resposta positiva e imediata a um choque de 1 p.p. na taxa de crescimento das despesas orçamentárias. Considerando as séries deflacionadas pelo deflator, os efeitos do choque sobre o PIB se dissipam após três anos; já a figura à direita, indica uma persistência de dois anos dessa repercussão.

Em condições semelhantes, os salários reais também apresentam resposta positiva, imediata e com duração de cerca de dez anos, em resposta a um choque de 1 p.p. na taxa de crescimento das despesas orçamentárias dos estados brasileiros. Portanto, esse resultado apresenta evidências em favor da aplicação dos modelos de tradição Novo Keynesiana (NK) no mercado de trabalho brasileiro (Pappa 2009). Vale destacar que, em estudo recente, Carvalho et al. (2013) também encontram resultados nessa direção para o Brasil.

\subsection{Choques nas Despesas Correntes}

Em seguida, analisam-se os modelos que utilizam a taxa de crescimento das despesas correntes como indicador fiscal. A Tabela A.2, em apêndice, apresenta o modelo estimado. Os resultados contemporâneos apontam que um aumento de 1 p.p. na taxa de crescimento das despesas correntes majoram em 0,065 p.p. e 0,18 p.p. o crescimento do PIB dos estados, respectivamente para as análises com deflator e IGP-DI, e aumentam em $0,06 \% 0,12 \%$ os salários reais na mesma ordem. Considerando um incremento de 1 p.p. na taxa de crescimento do PIB, os salários reais seriam majorados em $0,09 \%$, na análise que usa o deflator, e em $0,27 \%$, no modelo que usa IGP-DI.

Em seguida, procedeu-se à análise das AIRF's desses modelos. Como no modelo anterior, a Figura 2 mostra que o crescimento do PIB dos estados brasileiros responde positivamente a choques na taxa de crescimento das despesas correntes. Todavia, o choque praticamente se dissipa em um ano em ambos os modelos.

Em relação aos salários reais, também se observa uma resposta positiva e contemporânea a choques no crescimento dos gastos. Ainda como na aná-

\footnotetext{
${ }^{2}$ Como o indicador de salários reais encontra-se em logaritmo e os demais em nível, seus coeficientes são interpretados como semi elasticidades; ou seja $\frac{\partial \ln Y}{\partial X}=\frac{1 / Y . \partial Y}{\partial X}=\frac{\partial Y}{\partial X} \cdot \frac{1}{Y}$, que é uma semi-elasticidade.
} 
Figura 2: AIRF's dos modelos com despesa orçamentária, corrente e de investimento
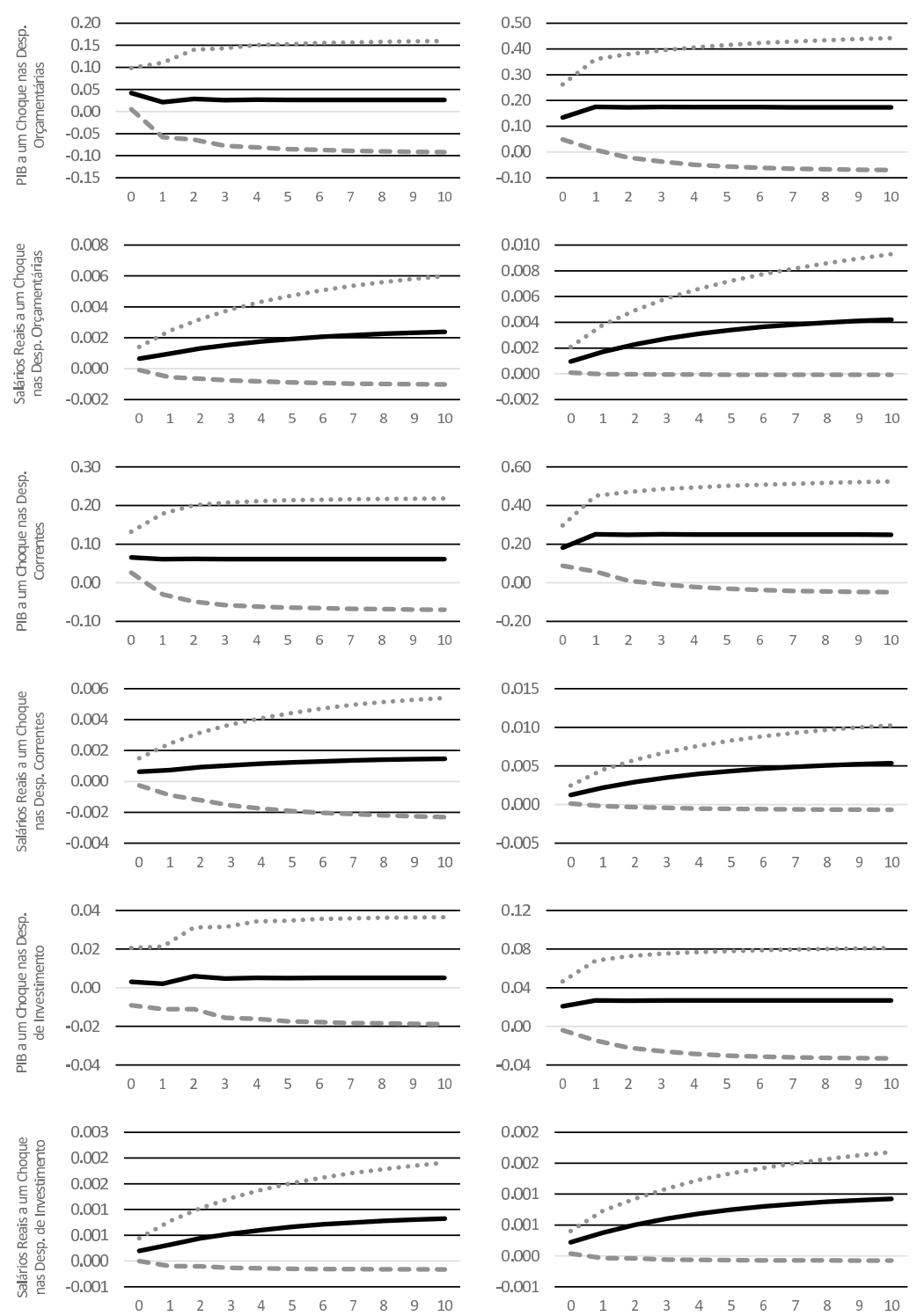

Fonte: Elaborado pelos autores. 
lise anterior, o efeito do choque se dissipa após dez anos. Esses resultados reforçam a aparente adequação dos modelos de tradição NK à realidade do mercado de trabalho dos estados brasileiros.

\subsection{Choques nas Despesas de Investimento}

Por fim, procedeu-se à análise dos resultados dos modelos que consideram a taxa de crescimento dos gastos de investimento como indicador fiscal. De modo semelhante às análises anteriores, inicialmente examina-se os coeficientes estruturais, ou os efeitos contemporâneos no sistema. Os resultados desses modelos estimados estão dispostos na Tabela A.3, em apêndice. Observa-se, no modelo que utiliza o deflator do PIB, que um aumento de 1 p.p. na taxa de crescimento das despesas de investimento aumenta em 0,003 p.p. o crescimento do PIB dos estados e em $0,02 \%$ os salários reais. Já na análise com as séries deflacionadas pelo IGP-DI, esses impactos foram de 0,02 p.p. e 0,02\%, respectivamente. Se o aumento de 1 p.p. fosse na taxa de crescimento do PIB, os salários reais seriam majorados em $0,09 \%$ e $0,3 \%$, respectivamente, nos modelos que usam o deflator e o IGP-DI.

Um fato a ser destacado é que, surpreendentemente, as respostas aos gastos com investimentos apresentaram magnitude inferior àquelas observadas nos resultados para os gastos correntes. Essas evidências podem indicar uma possível ineficiência do investimento público ou, ainda, dada a reconhecida demora para a maturação dos retornos dos investimentos públicos e o fato de que as AIRF's representam evidências de curto prazo, é possível que os impactos dos investimentos públicos não estejam representados em sua plenitude nesses resultados. Portanto, uma análise mais profunda sobre as peculiaridades dos investimentos públicos e suas repercussões sobre a atividade econômica e os salários reais nos estados brasileiros deve ser objeto de estudos futuros.

Em seguida, analisaram-se as AIRF's constantes na Figura 2. O crescimento do PIB responde de forma positiva e imediata, com o efeito do choque se dissipando após três anos. Um choque de 1 p.p. na taxa de crescimento dos gastos com investimento repercute de forma positiva e imediata sobre os salários reais e, como nos modelos anteriores, apresenta persistência de cerca de 10 anos.

\subsection{Exercícios de Robustez}

Para avaliar a robustez desses resultados e, também identificar possíveis assimetrias nessas respostas, além da análise efetuada para diferentes despesas e deflatores, realizaram-se alguns exercícios adicionais: (i) resultados para a sub amostra 2000-2010 (Figura A.1, em apêndice), (ii) modelos estimados apenas com os estados das regiões Norte e Nordeste (Figura A.2, em apêndice) e exercícios que incorporam apenas as unidades federativas constantes nas regiões Sudeste, Sul e Centro-Oeste (Figura A.3, em apêndice) e, por fim, (iii) modelos para as despesas de investimento e correntes que incorporem seus respectivos complementares ${ }^{3}$ (Figuras A.4 e A.5, em apêndice).

\footnotetext{
${ }^{3}$ A variável de complemento fiscal foi construída nos moldes de Bénétrix (2012). Logo, da despesa orçamentária, medida da absorção do governo estadual, é deduzido o gasto do modelo em questão. Para a estimação do modelo com despesas correntes, por exemplo, a variável de complemento fiscal é dada pela diferença entre a despesa orçamentária e a despesa corrente.
} 
Em termos gerais não foram observadas assimetrias nas respostas do PIB ou salários reais nas análises de robustez realizadas e, portanto, há fortes evidências de que o mercado de trabalho dos estados brasileiros comporta-se conforme os modelos de tradição Novo Keynesiana.

Além disso, observaram-se impactos de maior magnitude nos modelos com dados entre 2000-2010, logo, especula-se que ambientes de maior estabilidade econômica podem favorecer as repercussões dos gastos públicos sobre a atividade econômica e salários reais, quando comparado aos modelos com amostra completa. As evidências indicam ainda que essas políticas apresentam maiores impactos nas regiões Norte e Nordeste, quando comparadas às demais, resultados que podem indicar um mercado de trabalho menos dinâmico e mais dependente de estímulos por parte dos gestores estaduais.

Em resumo, os resultados das AIRF's para o PIB estão em consonância com os reportados por autores como Mountford \& Uhlig (2009) e Mertens \& Ravn (2010), que também encontram resultado nesse sentido. No que tange ao comportamento do salário real em resposta aos choques fiscais, resultados semelhantes foram observados para a economia americana por Galí et al. (2007), Ramey (2009), Pappa (2009). Para países da Zona do Euro, Forni et al. (2009) e Bénétrix (2012) também reportam resultado semelhante. Adicionalmente, Rotemberg \& Woodford (1992) e Monacelli \& Perotti (2008) apresentam evidências que corroboram esse resultado. Vale destacar que Carvalho et al. (2013) também encontram evidências nessa linha por meio da aplicação de DSGE e SVAR com dados nacionais para o Brasil.

Adicionalmente, os resultados indicam, ainda, que a síntese Novo Keynesiana parece explicar melhor a resposta do mercado de trabalho dos estados brasileiros à choques fiscais; ou seja, o incremento da demanda por trabalho se mostra superior ao da oferta de mão de obra em resposta ao aumento de gastos públicos, gerando um excesso de demanda por trabalho que, ceteris paribus, pressiona por um aumento nos salários reais (Pappa 2009).

Por fim, os resultados parecem indicar de modo robusto que tanto o PIB estadual quanto os salários reais respondem de forma positiva aos gastos públicos, com o impacto sobre o segundo se mostrando mais duradouro. Nesse sentido, as evidências observadas aqui apontam para a adequação da tradição NK, sobretudo no que tange aos efeitos dos choques fiscais sobre os salários reais. Entretanto, essas evidências devem ser vistas com cautela, uma vez que a partir desses modelos não se pode inferir se a produtividade do trabalho acompanha esse aumento salarial, pois, caso não haja aumento da produtividade em contrapartida ao aumento salarial, haverá um estrangulamento do setor produtivo, o que afetará os preços relativos, gerando pressão inflacionária e corroendo o poder de compra dos agentes econômicos, além de tornar obscuro o horizonte de previsão destes.

\section{Considerações Finais}

O presente estudo investigou os efeitos dos choques fiscais sobre PIB e salários reais em uma perspectiva regional para os estados brasileiros com dados entre 1995-2010 e modelos VAR em painel, estimados por mínimos quadrados com variáveis dummies (LSDV).

A contribuição potencial do artigo reside em apresentar evidências em âmbito regional desses efeitos, sobretudo nos salários reais, uma temática que 
está longe de consenso na literatura entre os modelos RBC (efeitos negativos) e a tradição NK (efeitos positivos), além da escassez de estudos dessa natureza sob a ótica regional que, como destaca Pappa (2009) e Partridge \& Rickman (2010), podem contribuir para o melhor entendimento dessas relações por examinar dados que não estão sujeitos a assimetrias de política monetária ou de regimes cambiais e, ainda, por facilitar a construção de painéis com dados de despesas públicas que sejam comparáveis.

Os resultados da análise das respostas do PIB estadual à choques fiscais indicam que a atividade econômica estadual responde de forma positiva e imediata a todas as despesas consideradas. Resultados nessa linha também foram obtidos por Mountford \& Uhlig (2009) e Mertens \& Ravn (2010). Esses achados confirmam os apontamentos dos modelos de linha Keynesiana que destacam a importância dos gastos públicos no crescimento do PIB.

As evidências apontam ainda que os salários reais também respondem positivamente aos choques nos gastos públicos orçamentários, correntes e de investimentos, ou seja, um resultado em consonância com a abordagem NK. Essa tradição argumenta que haverá um aumento da demanda por trabalho superior à oferta deste, gerando um excesso de demanda por trabalho que aumenta o poder de barganha dos trabalhadores e, consequentemente, os salários reais. Carvalho et al. (2013) obtêm evidências nessa direção para o Brasil; Forni et al. (2009) e Bénétrix (2012) para os países da zona do Euro e Galí et al. (2007), Ramey (2009) e Pappa (2009) para os Estados Unidos.

No entanto, apesar de esses achados se mostrarem robustos, esses resultados precisam ser examinados com prudência, já que a abordagem empregada nesse artigo não possibilita uma análise mais profunda do sistema econômico regional de modo a acompanhar se esses ganhos salariais foram acompanhados pela produtividade do trabalho. Em caso negativo, esse aumento salarial pode se mostrar danoso por desestimular o setor produtivo e gerar inflação que, por sua vez, prejudica o horizonte de previsão dos agentes econômicos e aumenta a variabilidade dos preços relativos.

Apesar de representar um esforço inicial nessa literatura regional aplicada ao Brasil, este estudo pode ser ampliado de várias formas. A principal delas seria empregar um modelo DSGE regional, como indicado por Partridge \& Rickman (2010), que possibilite a identificação de restrições aplicáveis em um sistema regional mais completo que possibilite acompanhar esses resultados sobre produtividade do trabalho.

\section{Referências Bibliográficas}

Aiyagari, S. R., Christiano, L. J. \& Eichenbaum, M. (1992), 'The output, employment, and interest rate effects of government consumption', Journal of Monetary Economics 30(1), 73-86.

Baxter, M. \& King, R. G. (1993), 'Fiscal policy in general equilibrium', The American Economic Review pp. 315-334.

Beetsma, R., Giuliodori, M. \& Klaassen, F. (2009), 'Temporal aggregation and SVAR identification, with an application to fiscal policy', Economics Letters 105(3), 253-255.

Bénétrix, A. S. (2012), 'Fiscal shocks and real wages', International Journal of Finance E Economics 17(3), 203-220. 
Blanchard, O. \& Perotti, R. (2002), 'An empirical characterization of the dynamic effects of changes in government spending and taxes on output', The Quarterly Journal of Economics 117(4), 1329-1368.

Burnside, C., Eichenbaum, M. \& Fisher, J. D. (2004), 'Fiscal shocks and their consequences', Journal of Economic Theory 115(1), 89-117.

Carvalho, D. B., Silva, M. E. A. \& Silva, I. E. M. (2013), 'Efeitos dos choques fiscais sobre o mercado de trabalho brasileiro', Revista Brasileira de Economia 67(2), 177-200.

Fisher, J. D. \& Peters, R. (2010), 'Using stock returns to identify government spending shocks', The Economic Journal 120(544), 414-436.

Forni, L., Monteforte, L. \& Sessa, L. (2009), 'The general equilibrium effects of fiscal policy: estimates for the Euro area', Journal of Public Economics 93(34), 559-585.

Galí, J., López-Salido, J. D. \& Vallés, J. (2007), 'Understanding the effects of government spending on consumption', Journal of the European Economic Association 5(1), 227-270.

Hahn, J. \& Kuersteiner, G. (2002), 'Asymptotically unbiased inference for a dynamic panel model with fixed effects when both $n$ and $T$ are large', Econometrica 70(4), 1639-1657.

Hall, P. (1992), The Bootstrap and Edgeworth Expansion, Springer, New York.

Im, K. S., Pesaran, M. H. \& Shin, Y. (2003), 'Testing for unit roots in heterogeneous panels', Journal of Econometrics 115(1), 53-74.

Levin, A., Lin, C.-F. \& Chu, C.-S. J. (2002), 'Unit root tests in panel data: asymptotic and finite-sample properties', Journal of Econometrics 108(1), 124.

Lobato, C. E. (2011), Política fiscal e monetária ótimas em um modelo de médio porte para o Brasil pós-plano Real, Master's thesis, Porto Alegre: UFRGS - Programa de Pós-graduação em Economia, Faculdade de Economia, Universidade Federal do Rio Grande do Sul.

Mertens, K. \& Ravn, M. O. (2010), 'Measuring the impact of fiscal policy in the face of anticipation: a structural VAR approach', The Economic Journal 120(544), 393-413.

Monacelli, T. \& Perotti, R. (2008), Fiscal policy, wealth effects, and markups, Technical report, National Bureau of Economic Research.

Monacelli, T. \& Perotti, R. (2010), 'Fiscal policy, the real exchange rate and traded goods', The Economic Journal 120(544), 437-461.

Mountford, A. \& Uhlig, H. (2009), 'What are the effects of fiscal policy shocks?', Journal of Applied Econometrics 24(6), 960-992.

Nikell, S. J. (1981), 'Biases in dynamic models with fixed effects', Econometrica 49, 1417-1426. 
Pappa, E. (2009), 'The effects of fiscal shocks on employment and the real wage', International Economic Review 50(1), 217-244.

Partridge, M. D. \& Rickman, D. S. (2010), 'Computable general equilibrium (CGE) modelling for regional economic development analysis', Regional Studies 44(10), 1311-1328.

Perotti, R. et al. (2005), Estimating the effects of fiscal policy in OECD countries, Technical Report 4842, CEPR Discussion Papers.

Ramey, V. A. (2009), Identifying government spending shocks: it's all in the timing, Technical report, National Bureau of Economic Research.

Ramey, V. A. (2011), 'Identifying government spending shocks: it's all in the timing', The Quarterly Journal of Economics 126(1), 1-50.

Ramey, V. A. \& Shapiro, M. D. (1998), Costly capital reallocation and the effects of government spending, in 'Carnegie-Rochester Conference Series on Public Policy', Vol. 48, Elsevier, pp. 145-194.

Rotemberg, J. J. \& Woodford, M. (1992), 'Oligopolistic pricing and the effects of aggregate demand on economic activity', Journal of political Economy 100(6), 1153-1207. 


\section{Apêndice A}

Figura A.1: AIRFs para análise de robustez com subamostra temporal 2000-2010
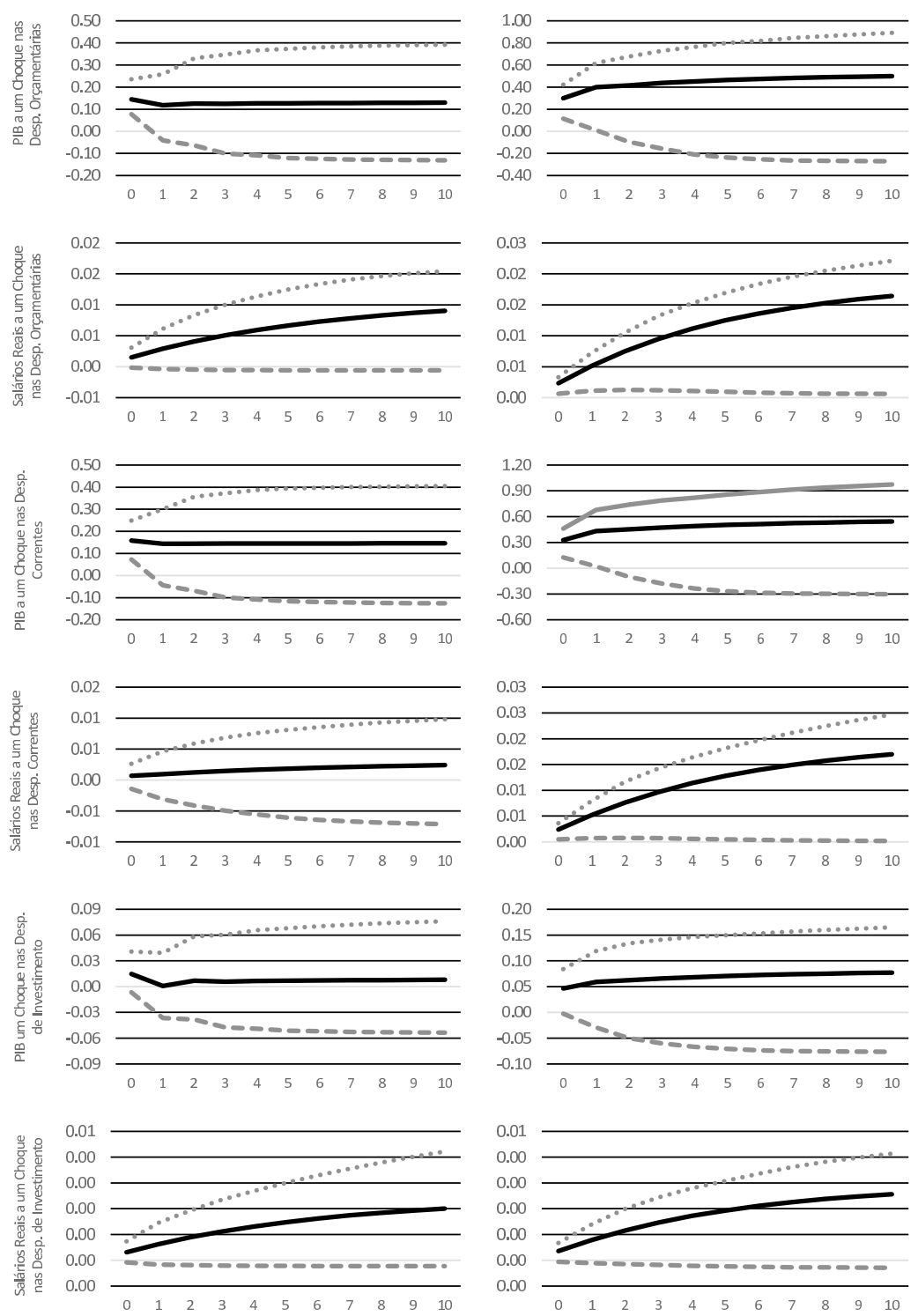

Fonte: Elaborado pelos autores. 
Tabela A.1: Modelos com gastos orçamentários

\begin{tabular}{|c|c|c|c|c|c|c|c|}
\hline \multicolumn{4}{|c|}{ Modelo com Aplicação do Deflator } & \multicolumn{4}{|c|}{ Modelo com Aplicação do IGP-DI } \\
\hline \multicolumn{4}{|c|}{$\begin{array}{l}\text { Efeitos Contemporâneos } \\
\text { (Parâmetros Estruturais) }\end{array}$} & \multicolumn{4}{|c|}{$\begin{array}{l}\text { Efeitos Contemporâneos } \\
\text { (Parâmetros Estruturais) }\end{array}$} \\
\hline- & $\gamma_{\text {GASTOS }}$ & $\gamma_{P I B}$ & $w$ & - & $\gamma_{\text {GASTOS }}$ & $\gamma_{P I B}$ & $w$ \\
\hline$\gamma_{\text {GASTOS }}$ & 1 & 0 & 0 & $\gamma_{\text {GASTOS }}$ & 1 & 0 & 0 \\
\hline$\gamma_{P I B}$ & 0,042 & 1 & 0 & $\gamma_{P I B}$ & 0,13 & 1 & \\
\hline$w$ & 0,0006 & 0,00079 & 1 & $w$ & 0,0009 & 0,0026 & 1 \\
\hline \multicolumn{4}{|c|}{ Equações com Efeitos Defasados } & \multicolumn{4}{|c|}{ Equações com Efeitos Defasados } \\
\hline- & $\gamma_{\text {GASTOS }}$ & $\gamma_{P I B}$ & $w$ & - & $\gamma_{\text {GASTOS }}$ & $\gamma_{P I B}$ & $w$ \\
\hline$\gamma_{\text {GASTOS }, t-1}$ & $\begin{array}{r}-0,35^{*} \\
(0,00)\end{array}$ & $\begin{array}{r}-0,020 \\
(0,18)\end{array}$ & $\begin{array}{l}0,00014 \\
(0,38)\end{array}$ & $\gamma_{\text {GASTOS }, t-1}$ & $\begin{array}{r}-0,30^{*} \\
(0,00)\end{array}$ & $\begin{array}{c}0,024 \\
(0,19)\end{array}$ & $\begin{array}{l}0,000034 \\
(0,83)\end{array}$ \\
\hline$\gamma_{P I B, t-1}$ & $\begin{array}{c}0,41 \\
(0,66)\end{array}$ & $\begin{array}{r}-0,019 \\
(0,52)\end{array}$ & $\begin{array}{l}-0,0012^{*} \\
(0,00)\end{array}$ & $\gamma_{P I B, t-1}$ & $\begin{array}{r}0,24^{*} \\
(0,00)\end{array}$ & $\begin{array}{r}0,12^{*} \\
(0,00)\end{array}$ & $\begin{array}{c}-0,0003 \\
(0,24)\end{array}$ \\
\hline$w_{t-1}$ & $\begin{array}{r}-4,94 \\
(0,64)\end{array}$ & $\begin{array}{l}2,15^{* *} \\
(0,05)\end{array}$ & $\begin{array}{r}0,80^{*} \\
(0,00)\end{array}$ & $w_{t-1}$ & $\begin{array}{r}-4,85 \\
(0,67)\end{array}$ & $\begin{array}{c}-0,42 \\
(0,92)\end{array}$ & $\begin{array}{r}0,79^{*} \\
(0,00)\end{array}$ \\
\hline$R^{2}$ & 0,14 & 0,09 & 0,95 & $R^{2}$ & 0,10 & 0,08 & 0,95 \\
\hline$F(3,361)$ & $\begin{array}{l}18,81^{*} \\
(0,00)\end{array}$ & $\begin{array}{l}16,97^{*} \\
(0,00)\end{array}$ & $\begin{array}{r}156,45^{*} \\
(0,00)\end{array}$ & $F(3,361)$ & $\begin{array}{l}13,01^{*} \\
(0,00)\end{array}$ & $\begin{array}{r}7,19^{*} \\
(0,00)\end{array}$ & $\begin{array}{c}147,69^{*} \\
(0,00)\end{array}$ \\
\hline Observação & 432 & 432 & 432 & Observação & 432 & 432 & 432 \\
\hline Grupos & 27 & 27 & 27 & Grupos & 27 & 27 & 27 \\
\hline Observação por Grupo & 16 & 16 & 16 & Observação por Grupo & 16 & 16 & 16 \\
\hline
\end{tabular}

Fonte: Elaborado pelos autores a partir dos resultados obtidos.

Nota 1: $\gamma_{\text {GASTOS }}$ - Taxa de crescimento dos gastos; $\gamma_{P I B}$ - Taxa de crescimento do PIB; $w$ - Salário real, em logaritmo.

Nota 2: p-valor entre parênteses. ${ }^{*}$ Significante a $1 \%$; ${ }^{* *}$ Significante a $5 \%$; ${ }^{* *}$ Significante a $10 \%$. 
Tabela A.2: Modelos com gastos correntes

\begin{tabular}{|c|c|c|c|c|c|c|c|}
\hline \multicolumn{4}{|c|}{ Modelo com Aplicação do Deflator } & \multicolumn{4}{|c|}{ Modelo com Aplicação do IGP-DI } \\
\hline \multicolumn{4}{|c|}{$\begin{array}{l}\text { Efeitos Contemporâneos } \\
\text { (Parâmetros Estruturais) }\end{array}$} & \multicolumn{4}{|c|}{$\begin{array}{c}\text { Efeitos Contemporâneos } \\
\text { (Parâmetros Estruturais) }\end{array}$} \\
\hline- & $\gamma_{\text {GASTOS }}$ & $\gamma_{P I B}$ & $w$ & - & $\gamma_{\text {GASTOS }}$ & $\gamma_{P I B}$ & $w$ \\
\hline$\gamma_{\text {GASTOS }}$ & 1 & 0 & 0 & $\gamma_{\text {GASTOS }}$ & 1 & 0 & 0 \\
\hline$\gamma_{P I B}$ & 0,065 & 1 & 0 & $\gamma_{P I B}$ & 0,18 & 1 & 0 \\
\hline$w$ & 0,0006 & 0,0009 & 1 & $w$ & 0,0012 & 0,0027 & 1 \\
\hline \multicolumn{4}{|c|}{ Equações com Efeitos Defasados } & \multicolumn{4}{|c|}{ Equações com Efeitos Defasados } \\
\hline- & $\gamma_{\text {GASTOS }}$ & $\gamma_{P I B}$ & $w$ & - & $\gamma_{\text {GASTOS }}$ & $\gamma_{P I B}$ & $w$ \\
\hline$\gamma_{\text {GASTOS }, t-1}$ & $\begin{array}{r}-0,27^{*} \\
(0,00)\end{array}$ & $\begin{array}{c}-0,0027 \\
(0,89)\end{array}$ & $\begin{array}{l}0,0003 \\
(0,16)\end{array}$ & $\gamma_{\text {GASTOSt }-1}$ & $\begin{array}{l}-0,22^{*} \\
(0,00)\end{array}$ & $\begin{array}{l}0,048^{* *} \\
(0,05)\end{array}$ & $\begin{array}{l}0,00002 \\
(0,92)\end{array}$ \\
\hline$\gamma_{P I B, t-1}$ & $\begin{array}{r}0,010 \\
(0,88)\end{array}$ & $\begin{array}{l}-0,021^{* *} \\
(0,05)\end{array}$ & $\begin{array}{l}-0,0011^{*} \\
(0,00)\end{array}$ & $\gamma_{P I B t-1}$ & $\begin{array}{c}0,16^{* *} \\
(0,02)\end{array}$ & $\begin{array}{r}0,12^{*} \\
(0,00)\end{array}$ & $\begin{array}{c}-0,0003 \\
(0,26)\end{array}$ \\
\hline$w_{t-1}$ & $\begin{array}{l}-1,79 \\
(0,82)\end{array}$ & $\begin{array}{c}-0,62 \\
(0,85)\end{array}$ & $\begin{array}{c}0,81^{*} \\
(0,00)\end{array}$ & $w_{t-1}$ & $\begin{array}{r}-1,12 \\
(0,89)\end{array}$ & $\begin{array}{r}-0,57 \\
(0,89)\end{array}$ & $\begin{array}{r}0,79^{*} \\
(0,00)\end{array}$ \\
\hline$R^{2}$ & 0,10 & 0,07 & 0,96 & $R^{2}$ & 0,07 & 0,08 & 0,96 \\
\hline$F(3,361)$ & $\begin{array}{l}11,19^{*} \\
(0,00)\end{array}$ & $\begin{array}{r}9,72^{*} \\
(0,00)\end{array}$ & $\begin{array}{r}157,35^{*} \\
(0,00)\end{array}$ & $F(3,361)$ & $\begin{array}{r}7,12^{*} \\
(0,00)\end{array}$ & $\begin{array}{r}7,96^{*} \\
(0,00)\end{array}$ & $\begin{array}{c}147,67^{*} \\
(0,00)\end{array}$ \\
\hline Observação & 432 & 432 & 432 & Observação & 432 & 432 & 432 \\
\hline Grupos & 27 & 27 & 27 & Grupos & 27 & 27 & 27 \\
\hline Observação por Grupo & 16 & 16 & 16 & Observação por Grupo & 16 & 16 & 16 \\
\hline
\end{tabular}

Fonte: Elaborado pelos autores a partir dos resultados obtidos.

Nota 1: $\gamma_{\text {GASTOS }}$ - Taxa de crescimento dos gastos; $\gamma_{P I B}$ - Taxa de crescimento do PIB; $w$ - Salário real, em logaritmo.

Nota 2: p-valor entre parênteses. ${ }^{*}$ Significante a $1 \%$; ${ }^{* *}$ Significante a $5 \%$; ${ }^{* *}$ Significante a $10 \%$. 
Tabela A.3: Modelos com gastos de investimento

\begin{tabular}{|c|c|c|c|c|c|c|c|}
\hline \multicolumn{4}{|c|}{ Modelo com Aplicação do Deflator } & \multicolumn{4}{|c|}{ Modelo com Aplicação do IGP-DI } \\
\hline \multicolumn{4}{|c|}{$\begin{array}{l}\text { Efeitos Contemporâneos } \\
\text { (Parâmetros Estruturais) }\end{array}$} & \multicolumn{4}{|c|}{$\begin{array}{l}\text { Efeitos Contemporâneos } \\
\text { (Parâmetros Estruturais) }\end{array}$} \\
\hline - & $\gamma_{\text {GASTOS }}$ & $\gamma_{P I B}$ & $w$ & - & $\gamma_{\text {GASTOS }}$ & $\gamma_{P I B}$ & $w$ \\
\hline$\gamma_{\text {GASTOS }}$ & 1 & 0 & 0 & $\gamma_{\text {GASTOS }}$ & 1 & 0 & 0 \\
\hline$\gamma_{P I B}$ & 0,003 & 1 & 0 & $\gamma_{P I B}$ & 0,02 & 1 & 0 \\
\hline$w$ & 0,0002 & 0,0009 & 1 & $w$ & 0,0002 & 0,003 & 1 \\
\hline \multicolumn{4}{|c|}{ Equações com Efeitos Defasados } & \multicolumn{4}{|c|}{ Equações com Efeitos Defasados } \\
\hline- & $\gamma_{\text {GASTOS }}$ & $\gamma_{P I B}$ & $w$ & - & $\gamma_{\text {GASTOS }}$ & $\gamma_{P I B}$ & $w$ \\
\hline$\gamma_{\text {GASTOS }, t-1}$ & $\begin{array}{r}-0,34^{*} \\
(0,00)\end{array}$ & $\begin{array}{l}-0,01^{*} \\
(0,00)\end{array}$ & $\begin{array}{l}0,00003 \\
(0,39)\end{array}$ & $\gamma_{\text {GASTOS }, t-1}$ & $\begin{array}{l}-0,32^{*} \\
(0,00)\end{array}$ & $\begin{array}{r}0,003 \\
(0,49)\end{array}$ & $\begin{array}{c}-0,00001 \\
(0,72)\end{array}$ \\
\hline$\gamma_{P I B, t-1}$ & $\begin{array}{c}0,08 \\
(0,83)\end{array}$ & $\begin{array}{r}-0,02 \\
(0,38)\end{array}$ & $\begin{array}{l}-0,0012^{*} \\
(0,00)\end{array}$ & $\gamma_{P I B, t-1}$ & $\begin{array}{c}0,38 \\
(0,22)\end{array}$ & $\begin{array}{c}0,14^{*} \\
(0,00)\end{array}$ & $\begin{array}{c}-0,0003 \\
(0,26)\end{array}$ \\
\hline$w_{t-1}$ & $\begin{array}{c}5,52 \\
(0,89)\end{array}$ & $\begin{array}{c}0,39 \\
(0,90)\end{array}$ & $\begin{array}{r}0,80^{*} \\
(0,00)\end{array}$ & $w_{t-1}$ & $\begin{array}{c}4,60 \\
(0,91)\end{array}$ & $\begin{array}{c}-0,11 \\
(0,97)\end{array}$ & $\begin{array}{r}0,80^{*} \\
(0,00)\end{array}$ \\
\hline$R^{2}$ & 0,14 & 0,06 & 0,96 & $R^{2}$ & 0,13 & 0,07 & 0,95 \\
\hline$F(3,361)$ & $\begin{array}{l}19,15^{*} \\
(0,00)\end{array}$ & $\begin{array}{l}3,06^{* *} \\
(0,03)\end{array}$ & $\begin{array}{r}156,42^{*} \\
(0,00)\end{array}$ & $F(3,361)$ & $\begin{array}{l}17,23^{*} \\
(0,00)\end{array}$ & $\begin{array}{r}6,76^{*} \\
(0,00) \\
\end{array}$ & $\begin{array}{r}147,76^{*} \\
(0,00)\end{array}$ \\
\hline Observação & 432 & 432 & 432 & Observação & 432 & 432 & 432 \\
\hline Grupos & 27 & 27 & 27 & Grupos & 27 & 27 & 27 \\
\hline Observação por Grupo & 16 & 16 & 16 & Observação por Grupo & 16 & 16 & 16 \\
\hline
\end{tabular}

Fonte: Elaborado pelos autores a partir dos resultados obtidos.

Nota 1: $\gamma_{\text {GASTOS }}$ - Taxa de crescimento dos gastos; $\gamma_{P I B}$ - Taxa de crescimento do PIB; $w$ - Salário real, em logaritmo.

Nota 2: p-valor entre parênteses. ${ }^{*}$ Significante a $1 \%$; ${ }^{* *}$ Significante a $5 \%$; ${ }^{* *}$ Significante a $10 \%$. 
Figura A.2: AIRFs para análise de robustez com modelos para as regiões Norte e Nordeste
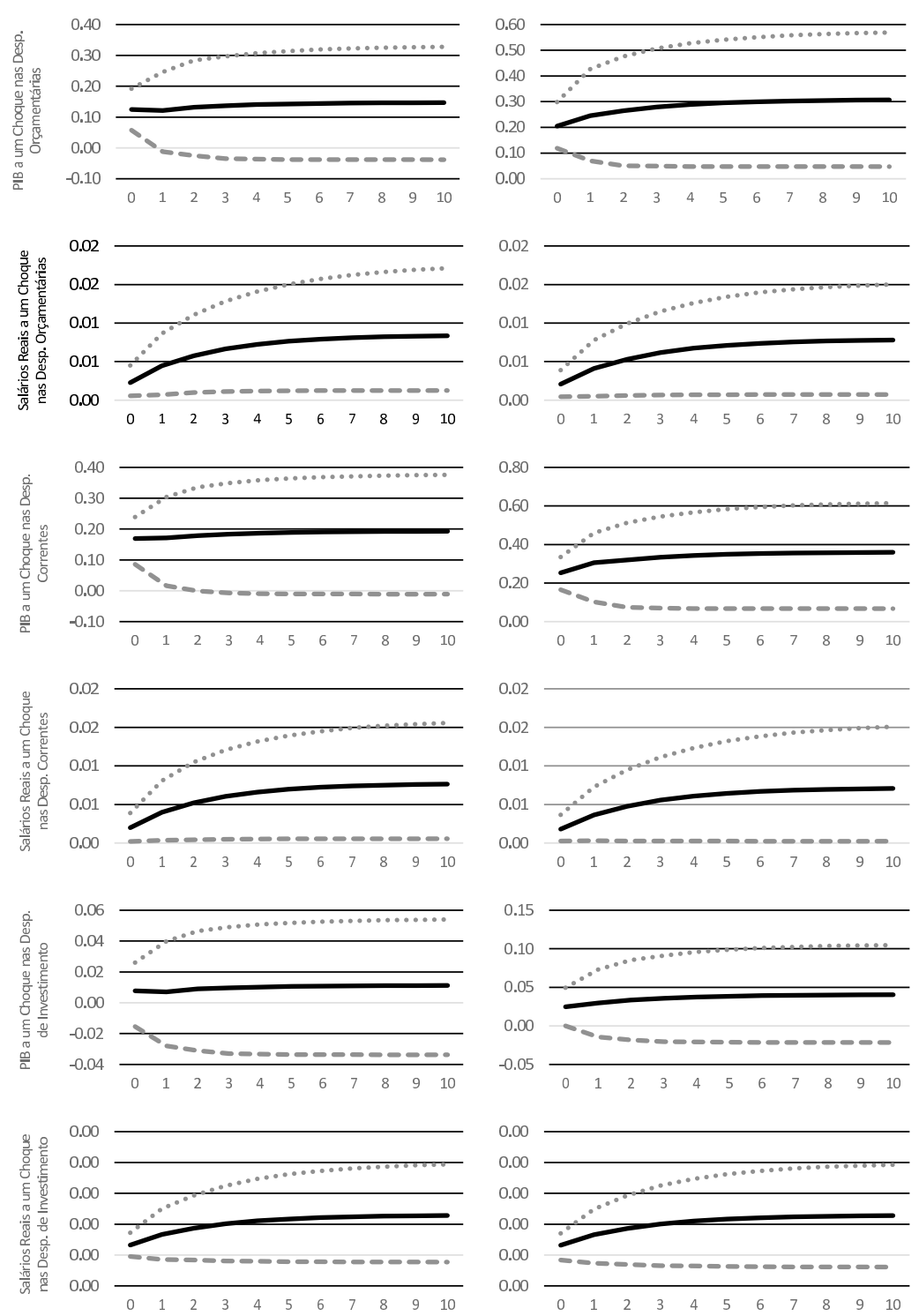

Fonte: Elaborado pelos autores. 
Figura A.3: AIRFs para análise de robustez com modelos para as regiões Sul, Sudeste e Centro-Oeste
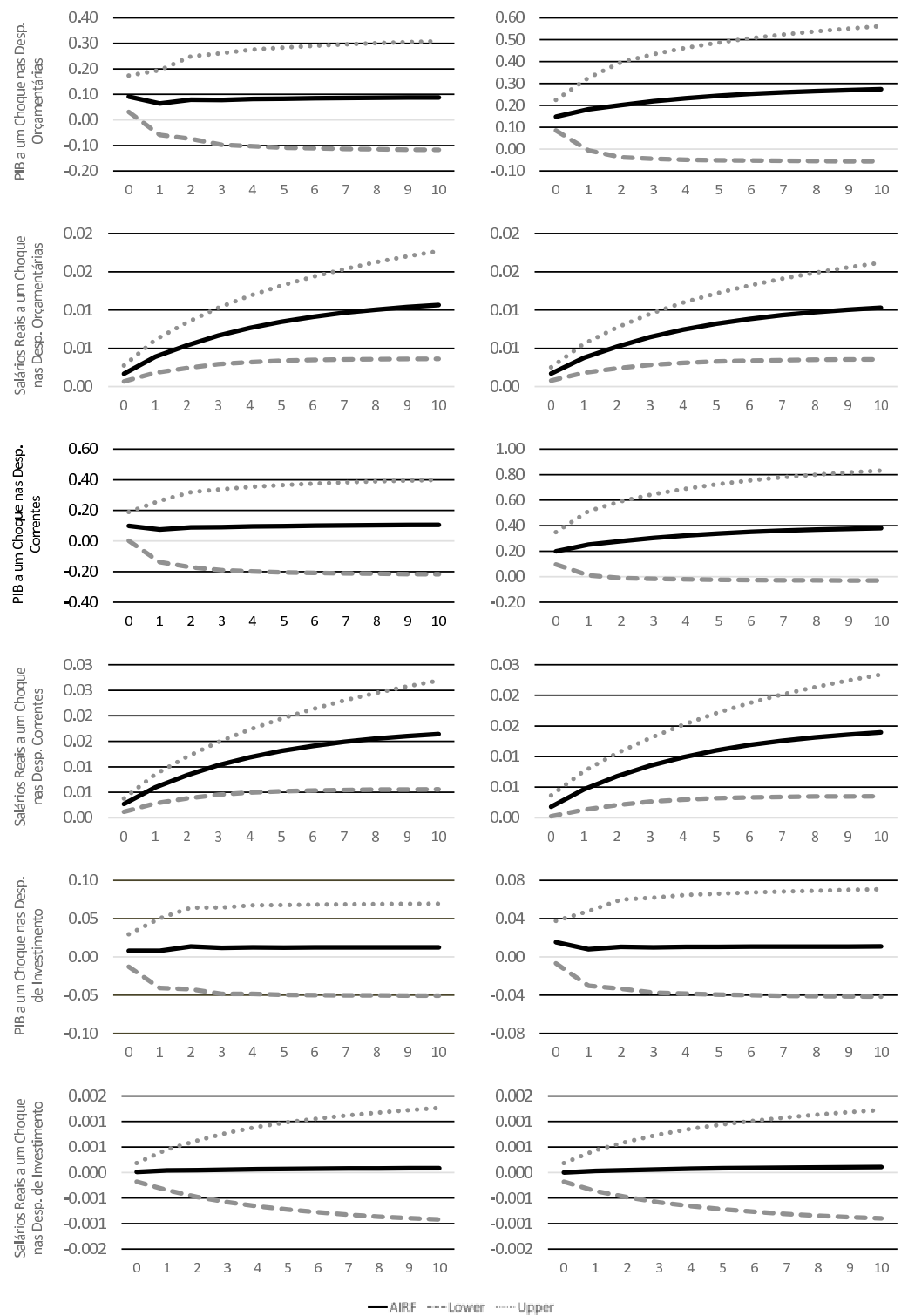

Fonte: Elaborado pelos autores. 
Figura A.4: AIRFs para análise de robustez com modelos adicionados de gastos complementares (modelo com despesas correntes)
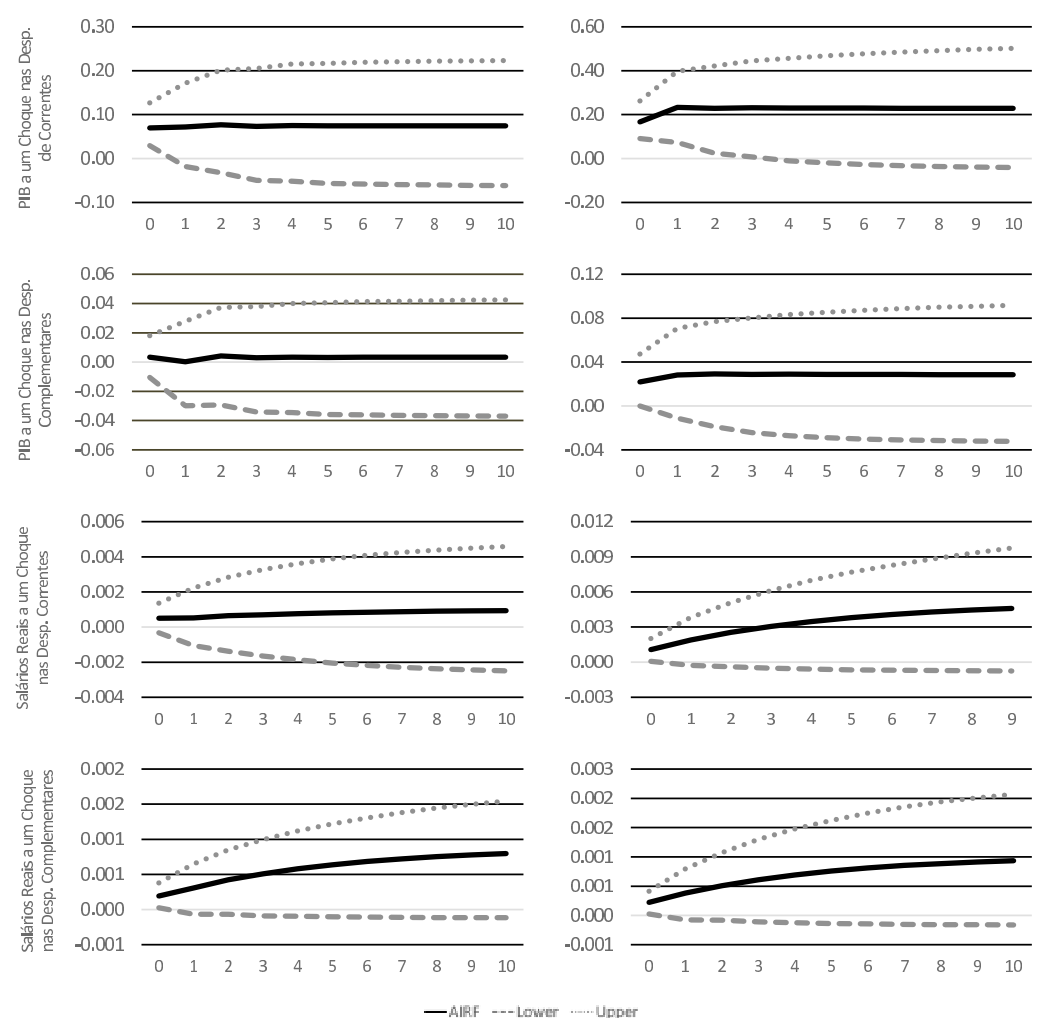

Fonte: Elaborado pelos autores. 
Figura A.5: AIRFs para análise de robustez com modelos adicionados de gastos complementares (modelo com despesas de investimento)
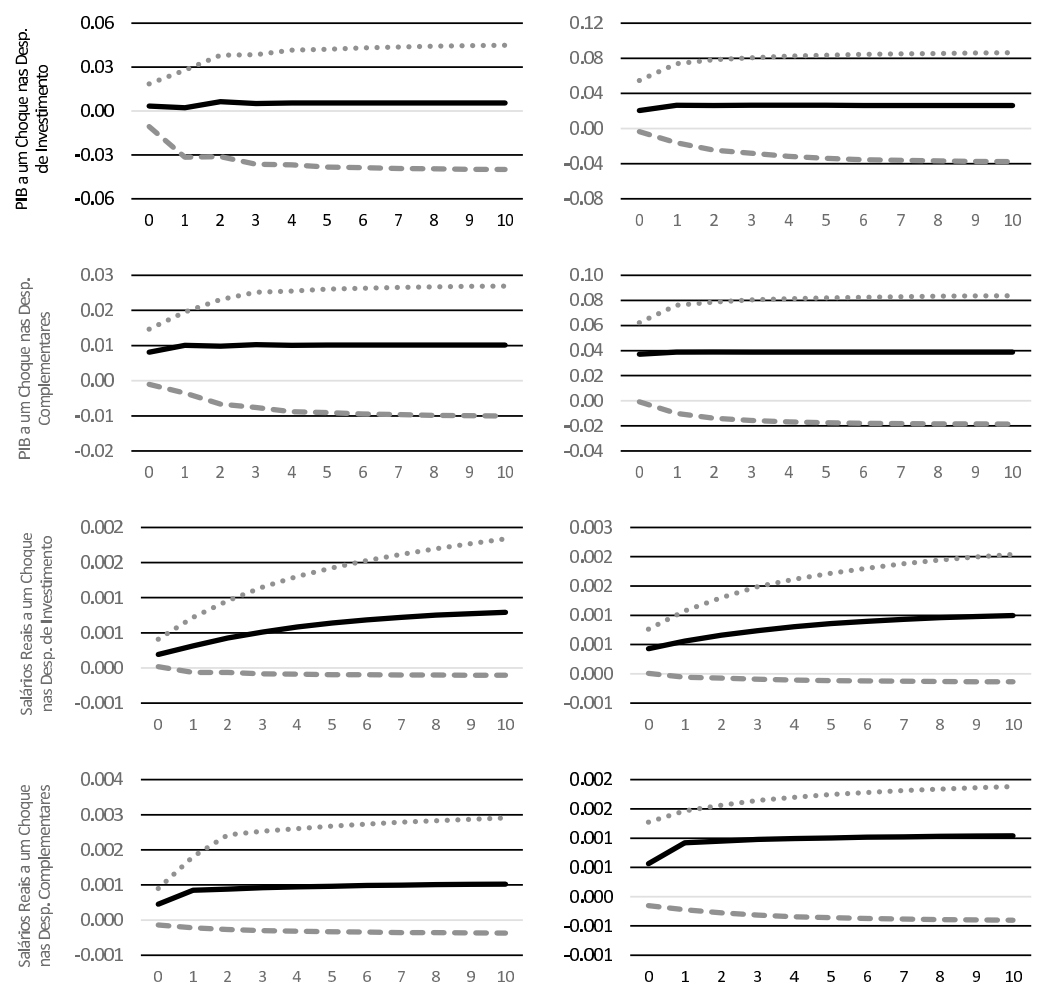

Fonte: Elaborado pelos autores. 
